Check for updates

Cite this: RSC Adv., 2019, 9, 40397

Received 5th September 2019

Accepted 29th October 2019

DOI: 10.1039/c9ra07109a

rsc.li/rsc-advances

\section{Ultrahigh permeance of a chemical cross-linked graphene oxide nanofiltration membrane enhanced by cation $-\pi$ interaction $\uparrow$}

\author{
Ruobing Yi, (D) a Rujie Yang, ${ }^{\mathrm{b}}$ Risheng Yu, ${ }^{\mathrm{b}}$ Jian Lan, ${ }^{\mathrm{c}}$ Junlang Chen, (D) ${ }^{\mathrm{b}}$ Zhikun Wang, ${ }^{\mathrm{b}}$ \\ Liang Chen (D)*b and Minghong Wu*a
}

Cross-linking with large flexible molecules is a common method to improve the stability and control the interlayer spacing of graphene oxide (GO) membranes, but it still suffers from the limitation of low water flux. Herein, a novel high flux GO membrane was fabricated using a pressure-assisted filtration method, which involved a synergistic chemical cross-linking of divalent magnesium ions and 1,6-hexanediamine (HDA) on a polyethersulfone (PES) support. The membrane cross-linked with magnesium ions and HDA $\left(\mathrm{GO}_{\mathrm{HDA}-\mathrm{Mg}^{2+}}\right)$ exhibited a high water flux up to $144 \mathrm{~L} \mathrm{~m}^{-2} \mathrm{~h}^{-1} \mathrm{bar}^{-1}$, about 7 times more than that of cross-linked GO membranes without adding magnesium ions ( $\left.\mathrm{GO}_{\mathrm{HDA}}\right)$, while keeping excellent rejection performance. The $\mathrm{GO}_{\mathrm{HDA}-\mathrm{Mg}^{2+}}$ membrane also showed an outstanding stability in water for a long time. The effects of magnesium ions on the $\mathrm{GO}_{\mathrm{HDA}-\mathrm{Mg}^{2+}}$ membrane were analyzed using several characterization methods, including Fourier transform infrared spectroscopy (FT-IR), scanning electron microscopy (SEM), X-ray photoelectron spectroscopy (XPS) and X-ray diffraction (XRD). The results indicated that magnesium ions not only promoted reasonable cross-linking, but also improved the stacking of GO sheets to give lower mass transfer resistance channels for water transport in the membranes, resulting in the ultrahigh permeance of the GO membranes.

\section{Introduction}

Graphene oxide (GO) is a two-dimensional network with a thickness of one atom, which has great potential in the field of water treatment because of its excellent hydrophilicity, ${ }^{1}$ remarkable stacking property ${ }^{2}$ and other unique properties. ${ }^{3}$ In GO membranes, a large number of oxygen-containing functional groups, such as hydroxyl, epoxy, carboxyl and carbonyl, are randomly distributed outside the pristine graphitic $\mathrm{sp}^{2}$ region. ${ }^{4}$ These oxygen functional groups act as water nanochannel spacers to introduce water molecules into the $\mathrm{sp}^{2}$ region which can allow water molecules to flow without resistance. ${ }^{5}$ Therefore, GO-based membranes are considered as the next generation of nanofiltration membranes.

In the practical application of GO nanofiltration membranes, the interlayer spacing between the neighboring GO nanosheets, water flux, efficient rejection and stable

${ }^{a}$ Shanghai Applied Radiation Institute, Shanghai University, Shanghai 200444, P. R. China.E-mail:mhwu@shu.edu.cn

${ }^{b}$ Department of Optical Engineering, Zhejiang A\&F University, Lin'an, Zhejiang 311300, P. R. China. E-mail: liang_chen05@126.com

${ }^{c}$ College of Pharmaceutical Chemistry and Materials Engineering, Taizhou University, Taizhou, Zhejiang 317000, China

$\dagger$ Electronic supplementary information (ESI) available. See DOI: 10.1039/c9ra07109a performance of the membrane are all crucial in water purification. ${ }^{6,7}$ However, the GO membrane is prone to swelling in water due to the large number of hydrophilic oxygen functional groups, which is not conducive to the stable performance of GO membrane in practical application. ${ }^{8}$ There have been many effective efforts to stabilize the interlayer spacing and prevent the swelling tendency of GO membranes. For example, by crosslinking with organic large molecules and ions, ${ }^{6,9-11}$ as well as by reducing the GO membrane to decrease the interlayer spacing, the stability is significant improved. ${ }^{7,12}$ Despite the great progress, these membranes still suffer from limitation of low water flux $\left(<27 \mathrm{~L} \mathrm{~m}^{-2} \mathrm{~h}^{-1} \mathrm{bar}^{-1}\right)^{2,13,14}$ The decreasing of the interlayer spacing and excessive cross-linking between sheets, not only decrease the water channel, ${ }^{7,10,11}$ but also increase the mass transfer resistance, ${ }^{9}$ leading to the low permeance. Therefore, GO membranes is still under the expectation, which requires further increase of water flux without sacrificing stability and rejection. ${ }^{2}$ These challenges hinder the potential applications of GO membranes in water purification.

In our previous work, accurate cationic control of the interlayer spacing of GO membranes with Ångström precision using ions, has been achieved..$^{11}$ The existence of cations adsorbed on GO surface, can greatly improve the flatness of the GO nanosheets, which is conducive to the stacking of GO sheets to form reasonable water nanochannels. ${ }^{11,15}$ Therefore, chemical crosslinking together with ions, potentially promoting reasonable 
cross-linking and improving the water channels of membrane in terms of flatness and surface with low mass transfer resistance.

For $\mathrm{Mg}^{2+}$, it is the most divalent cation and abundant in seawater, which has the same strong cation $-\pi$ interaction with the graphene sheets as the high multivalence metal ions $\left(\mathrm{Fe}^{2+}\right.$, $\mathrm{Co}^{2+}, \mathrm{Cu}^{2+}, \mathrm{Cd}^{2+}, \mathrm{Cr}^{2+}$ and $\mathrm{Pb}^{2+}$ ) have. ${ }^{16}$ Interestingly, GO membranes controlled by $\mathrm{Mg}^{2+}$ ions have the largest interlayer spacing compared with other metal ions in seawater. ${ }^{11}$ The large interlayer spacing in GO membrane is the prerequisite for ultrahigh water permeation. However, due to strong cation- $\pi$ interaction between $\mathrm{Mg}^{2+}$ and GO flakes, $\mathrm{Mg}^{2+}$ ions can be adsorbed on the GO surface during the cross-linking process, which can prevent excessive chemical cross-linking and improve the water channels of membrane in terms of flatness and low mass transfer resistance surface during the crosslinking reaction.

In this study, the GO membrane with high water permeance for dyes rejection was prepared by pressure-assisted filtration method, which was a synergistic chemical cross-linking of divalent magnesium $\left(\mathrm{Mg}^{2+}\right)$ ions and hexamethylenediamine (HDA) $\left(\mathrm{GO}_{\mathrm{HDA}-\mathrm{Mg}^{2+}}\right)$ on a polyethersulfone (PES) support. We also prepared the cross-linking GO membrane only by HDA for comparison ( $\left.\mathrm{GO}_{\mathrm{HDA}}\right)$.

\section{Experimental}

\section{Preparation graphene oxide (GO) suspension}

Graphene oxide (GO) was prepared from commercial graphite powder by a modified Hummers' method as previously re-

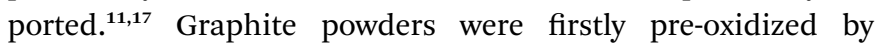
concentrated $\mathrm{H}_{2} \mathrm{SO}_{4}, \mathrm{~K}_{2} \mathrm{~S}_{2} \mathrm{O}_{8}$, and $\mathrm{P}_{2} \mathrm{O}_{5}$ solution with continuous stirring for 4.5 hours. Secondly the mixture suspension was washed by DI water and vacuum drying for a night. Then, oxide graphite was further oxidized in concentrated $\mathrm{H}_{2} \mathrm{SO}_{4}$ and $\mathrm{KMnO}_{4}$, diluted with a lot of DI water. $30 \% \mathrm{H}_{2} \mathrm{O}_{2}$ is further trickled to remove excess $\mathrm{KMnO}_{4}$. The product was separated by centrifugation and washed with $1: 10 \mathrm{HCl}$ aqueous solution and DI water. Finally, the GO suspension was prepared after half an hour of ultrasound.

\section{Preparation cross-linking GO membrane}

$\mathrm{MgCl}_{2}$ were added into $150 \mathrm{mg} \mathrm{L}{ }^{-1} \mathrm{GO}$ and stirred evenly. The concentration of $\mathrm{Mg}^{2+}$ in the mixed suspension was $0.25 \mathrm{M}$, $0.125 \mathrm{M}, 0.05 \mathrm{M}, 0.025 \mathrm{M}$ and $0 \mathrm{M}$, respectively. Next, 1,6-hexanediamine was dissolved in the above mixed suspension to prepared $0.075 \mathrm{M}$ aqueous solution. The mixtures were left to rest overnight at room temperature, $3 \mathrm{~mL}$ solution was dissolved to $40 \mathrm{~mL}$, respectively. Then, they were filtered through a polyethersulfone (PES) membrane under a pressure of 1 bar. Finally, the membranes were washed with $1: 10 \mathrm{HCl}$ aqueous solution and DI water. The membranes prepared at a series of concentrations of $\mathrm{Mg}^{2+}$ were named as $\mathrm{GO}_{\mathrm{HDA}-0.25 \mathrm{Mg}^{2+}}, \mathrm{GO}_{\mathrm{HDA}-}$ $0.125 \mathrm{Mg}^{2+}, \mathrm{GO}_{\mathrm{HDA}-0.05 \mathrm{Mg}^{2+}}, \mathrm{GO}_{\mathrm{HDA}-0.025 \mathrm{Mg}^{2+}}$ and $\mathrm{GO}_{\mathrm{HDA}}$, respec-

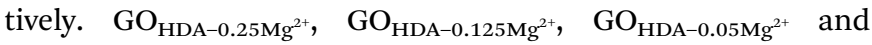
$\mathrm{GO}_{\mathrm{HDA}-0.025 \mathrm{Mg}^{2+}}$ are collectively referred to as $\mathrm{GO}_{\mathrm{HDA}-\mathrm{Mg}^{2+}}$.

\section{Filtration experiment}

The permeation and rejection performance of the cross-linking membranes were tested by using a vacuum filter system with an effective membrane area of $11.34 \mathrm{~cm}^{2}$. The rejection tests were performed with $10 \mathrm{mg} \mathrm{mL}^{-1}$ rhodamine B (RB), pararosaniline (PR), and methyl blue (MB) solutions, respectively. The molecular weights of the three dyes are 479.01, 323.82 and $319.86 \mathrm{~g}$ $\mathrm{mol}^{-1}$, respectively. When filtration went steady, the water flux $\left(J_{\mathrm{w}}\right)$ and Rejection $(R)$ was measured at 1 bar by using the following eqn (1) and (2):

$$
\begin{gathered}
J_{\mathrm{w}}=\frac{V}{\Delta t \times A \times P} \\
R=\left(1-\frac{C_{\mathrm{p}}}{C_{\mathrm{f}}}\right) \times 100 \%
\end{gathered}
$$

where $J_{\mathrm{w}}$ is the water flux $\left(\mathrm{L} \mathrm{m}^{-2} \mathrm{~h}^{-1} \mathrm{bar}^{-1}\right), V$ is the volume of the permeation water $(\mathrm{L}), A$ is the effective membrane area $\left(\mathrm{m}^{2}\right)$. $\Delta t$ is the permeation time (h) and the $P$ is the filtration pressure (bar). $C_{\mathrm{p}}$ and $C_{\mathrm{f}}$ are the concentration of permeation and feed dye solution which were measured by ultraviolet spectrophotometry, respectively.

\section{Results and discussion}

\section{The chemical properties of GO and cross-linking GO membrane}

The FT-IR spectra of the GO, $\mathrm{GO}_{\mathrm{HDA}-0.25 \mathrm{Mg}^{2+}}$ and $\mathrm{GO}_{\mathrm{HDA}}$ are shown in Fig. 1b. The chemical structure of GO was clearly changed by HDA. The FTIR spectrum of the pristine GO suggested the presence typical vibrations, such as, the hydroxyl C$\mathrm{OH}$ (stretching at $3594 \mathrm{~cm}^{-1}$ ), carbonyl $\mathrm{C}=\mathrm{O}$ (stretching at $1730 \mathrm{~cm}^{-1}$ ), carboxyl $-\mathrm{OH}$ (bending at $1418 \mathrm{~cm}^{-1}$ ), aromatic (stretching vibrations at $1622 \mathrm{~cm}^{-1}$ ) and epoxy $\mathrm{C}-\mathrm{O}$ (stretching at 1020-1227 $\left.\mathrm{cm}^{-1}\right) \cdot{ }^{18-21}$ For $\mathrm{GO}_{\mathrm{HDA}-0.25 \mathrm{Mg}^{2+}}$ and $\mathrm{GO}_{\mathrm{HDA}}$, the peaks of hydroxyl, epoxy and carboxyl decreased dramatically after cross-linking with HDA, and a new absorption peak was observed at $1550 \mathrm{~cm}^{-1}$ which represent the bending vibration of $\mathrm{N}-\mathrm{H} .^{\mathbf{9 , 1 0 , 2 2}}$ The reduction of hydroxyl, epoxy and carboxyl groups and the new generation of amine confirmed that HDA likely reacts with these oxygen-containing groups to form $\mathrm{C}-\mathrm{N}$ covalent bonds, during the condensation reaction of HDA with hydroxyl $^{23}$ and carboxyl ${ }^{24}$ and the nucleophilic addition reaction of amine with epoxy. ${ }^{24}$ In addition, compared with the $\mathrm{GO}_{\mathrm{HDA}}$, the $\mathrm{GO}_{\mathrm{HDA}-0.25 \mathrm{Mg}^{2+}}$ has more oxygen-containing groups and less amine groups, indicating a weaker reduction and lower degree of cross-linking due to $\mathrm{Mg}^{2+}$ added in the reaction process.

To further reveal the chemical properties of GO membranes, C 1s of XPS spectra were used to analyze the elemental compositions of the chemical bonds. As shown in Fig. 1d-f, the deconvoluted $\mathrm{C}$ 1s spectra were divided into four peaks at binding energies of 284.6, 286.7, 287.8, $288.9 \mathrm{eV}$, which corresponded with $\mathrm{C}=\mathrm{C} / \mathrm{C}-\mathrm{C}, \mathrm{C}-\mathrm{O} / \mathrm{C}-\mathrm{O}-\mathrm{C}, \mathrm{C}=\mathrm{O}$ and $\mathrm{O}=\mathrm{C}-\mathrm{O}$, respectively. ${ }^{7,25,26}$ The contents of $\mathrm{C}-\mathrm{O}-\mathrm{C} / \mathrm{C}-\mathrm{O}$ were $40.87 \%$, $34.04 \%$ and $27.23 \%$ for $\mathrm{GO}, \mathrm{GO}_{\mathrm{HDA}}$ and $\mathrm{GO}_{\mathrm{HDA}-0.25 \mathrm{Mg}^{2+}}$ respectively, which significantly decreased by cross-linking. And the intensities of $\mathrm{O}=\mathrm{C}-\mathrm{O}$ were also decreased dramatically. 
a
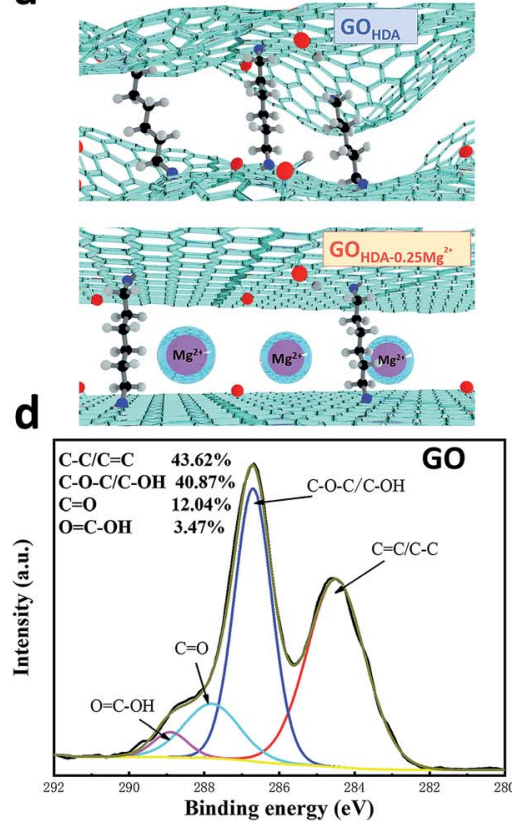

b

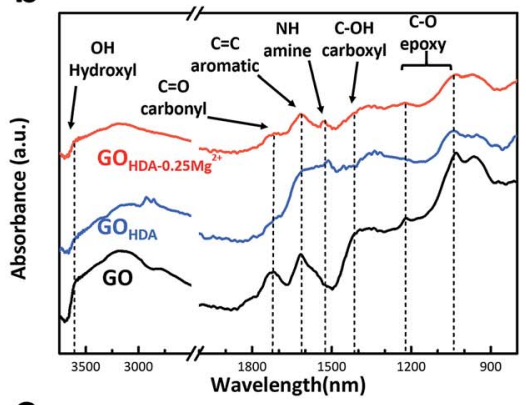

e

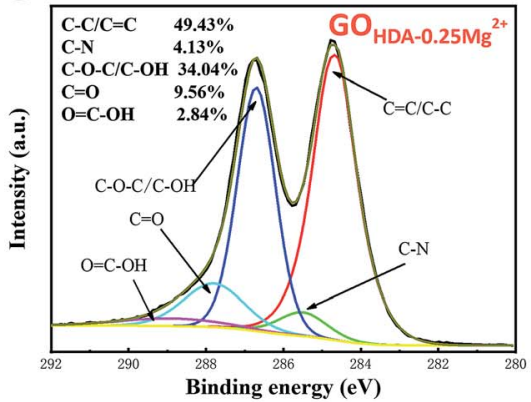

C

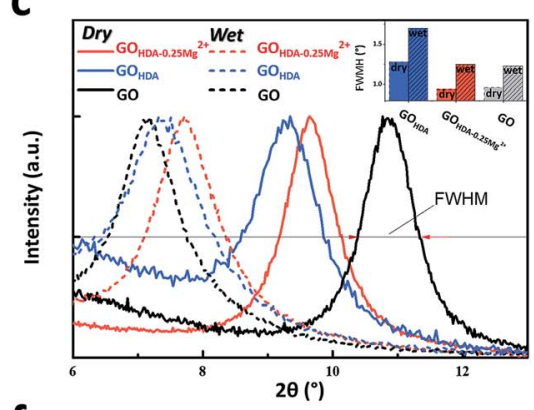

f

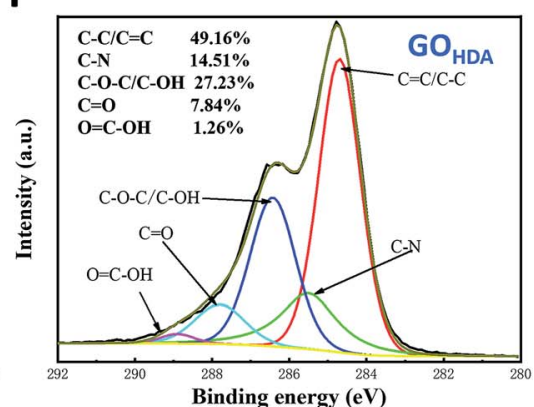

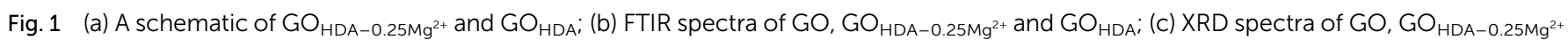

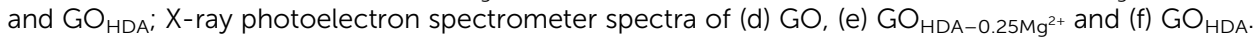

Importantly, a new peak appears at $285.5 \mathrm{eV}$ representing the $\mathrm{C}-\mathrm{N}$ bond, ${ }^{9,10}$ which are $4.13 \%$ and $14.51 \%$ for $\mathrm{GO}_{\mathrm{HDA}-0.25 \mathrm{Mg}^{2+}}$ and $\mathrm{GO}_{\mathrm{HDA}}$, respectively. The results demonstrated that the $\mathrm{GO}_{\mathrm{HDA}-0.25 \mathrm{Mg}^{2+}}$ has an effective cross-linking similar to $\mathrm{GO}_{\mathrm{HDA}}$, while a weaker reduction and lower degree of cross-linking, which is consistent with our FT-IR spectra results. It indicates that under the interaction of $\mathrm{Mg}^{2+}$, it is beneficial to reasonable cross-linking between GO and HDA. It not only ensures the stability of the membrane, but also facilitates the formation of channels with low mass transfer resistance.

In addition, we used XPS to detect the atomic concentrations. Fig. S2b† shows the survey XPS scans of the prepared cross-linked membranes. We can see that there are no observable $\mathrm{Mg}^{2+}$ ion signals. During the filtration, the filtrates were collected when the filtration process went steady (after about 20 min), which can help to rule out the adsorption effect by the membrane. Thus, the high rejection for dyes remained constant with increasing membrane thickness, is mainly due to stable size exclusion effect based on stable chemical cross-linking with HDA and the water channels of membrane improved by $\mathrm{Mg}^{2+}$ during the cross-linking reaction.

\section{Effects of $\mathrm{Mg}^{2+}$ on the interlayer spacing of cross-linked GO}

As mentioned above, the water channel of membrane is an important parameter for permeation. These membranes were further analyzed by XRD. There were clear shifts of the interlayer spacing (indicated by the Bragg peaks of XRD) relative to the GO membrane that had been immersed in pure water, as shown in Fig. 1c. Immersion in pure water resulted in a GO membrane spacing from $8.5 \AA$ to $12.8 \AA$, consistent with early reports. ${ }^{11}$ In contrast, the shifts of interlayer spacing of $\mathrm{GO}_{\mathrm{HDA}}$ and $\mathrm{GO}_{\mathrm{HDA}-0.25 \mathrm{Mg}^{2+}}$ between dry and wet state were smaller. The interlayer spacing of $\mathrm{GO}_{\mathrm{HDA}}$ were $9.3 \AA$ and $11.9 \AA$ in dry and wet state, respectively, due to the limitation of newly formed $\mathrm{C}-\mathrm{N}$ bonds between the GO sheets. ${ }^{\mathbf{9} 10}$ Similarly, those of $\mathrm{GO}_{\mathrm{HDA}-0.25 \mathrm{Mg}^{2+}}$ in dry and wet state were $9.1 \AA$ and $11.4 \AA$. However, as shown in the inset of Fig. 1c, the full width at half maxim (FWHM) of $\mathrm{GO}_{\mathrm{HDA}-0.25 \mathrm{Mg}^{2+}}$ is obviously narrower than that of $\mathrm{GO}_{\mathrm{HDA}}$, indicating that $\mathrm{GO}_{\mathrm{HDA}-0.25 \mathrm{Mg}^{2+}}$ has better uniformity of the water channel, than that of the $\mathrm{GO}_{\mathrm{HDA}}$ membrane. Thus, the channel can be shown in the schematic of Fig. 1a. The rippling and wrinkled structure was aligned flattened by $\mathrm{Mg}^{2+}$, which is conducive to the stacking of GO sheets to form a surface with low mass transfer resistance for water transport. ${ }^{\mathbf{1 1}, \mathbf{1 5}}$ Therefore, it can be predicted that the $\mathrm{GO}_{\mathrm{HDA}-0.25 \mathrm{Mg}^{2+}}$ membrane has a relatively high permeance while maintaining high rejection.

\section{Morphology of the GO and cross-linking GO}

The Atomic Force Microscope (AFM) image of GO flakes was observed, as shown in Fig. S2a. $\uparrow$ The thickness of GO monolayer is about $0.96 \mathrm{~nm}$. Fig. 2a-f show the SEM images of surface and cross-section morphology of the GO, $\mathrm{GO}_{\mathrm{HDA}}$ and $\mathrm{GO}_{\mathrm{HDA}-0.25 \mathrm{Mg}^{2+}}$ membranes. The thickness of the cross-linked membrane was about $200 \mathrm{~nm}$, while the thickness of GO membrane was $150 \mathrm{~nm}$. These SEM images showed that the resulting thin layered membrane was continuous and free of macro pores or defects, which is critical for a highly efficient separation process. ${ }^{11}$ As shown in Fig. $2 \mathrm{f}, \mathrm{GO}_{\mathrm{HDA}-0.25 \mathrm{Mg}^{2+}}$ membrane is obviously a multi-layers structure like GO membrane. As shown 
a

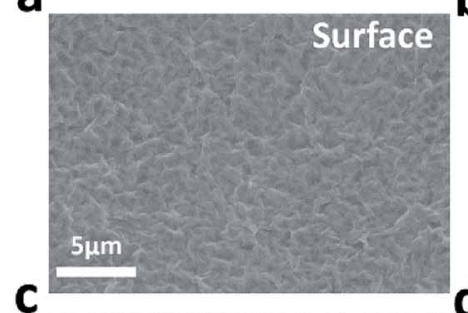

C

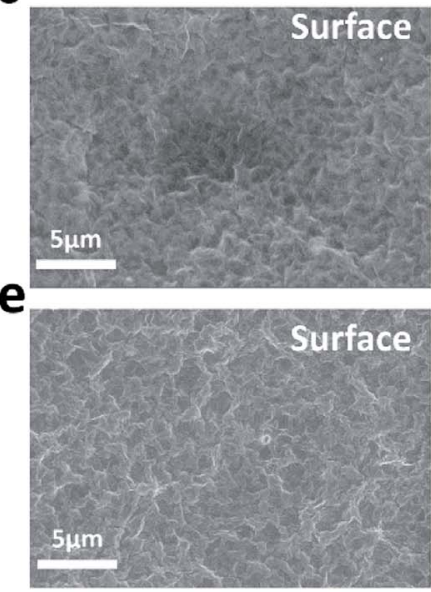

b
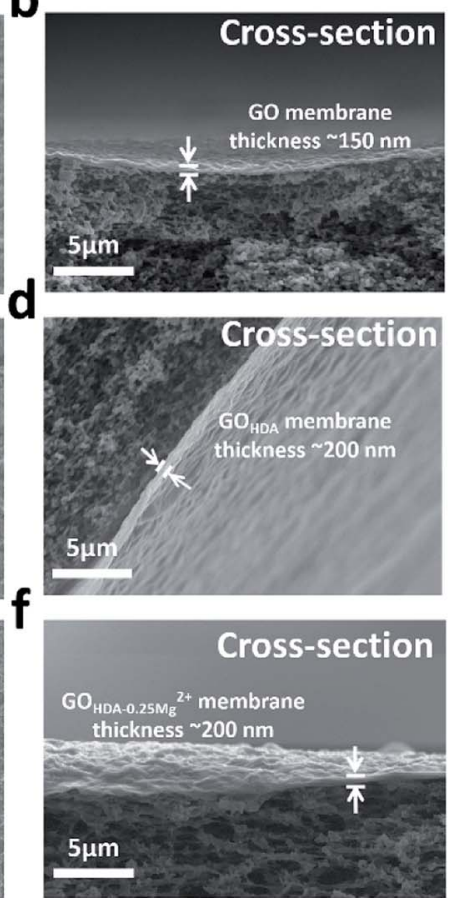

g

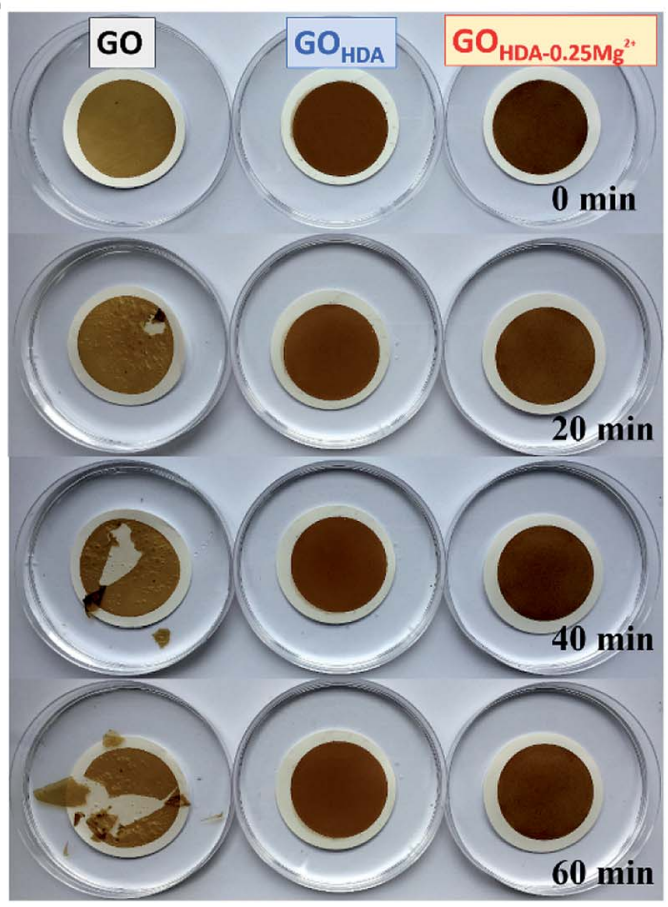

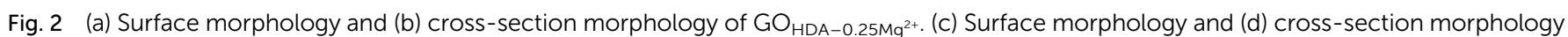
of GO. (e) Surface morphology and (f) cross-section morphology of $\mathrm{GO}_{\mathrm{HDA}}$. (g) Stability of GO, GO $\mathrm{HDA}_{\text {and }} \mathrm{GO}_{\mathrm{HDA}-0.25 \mathrm{Mg}^{2+}}$ membranes in water. These pictures were taken after the water had been stirred with a glass stirring rod.

in Fig. $2 \mathrm{~g}$, we also evaluated the stability of the membrane immersed in water. The GO membrane disintegrated after 20 min without mechanical stirring, and then seriously dispersed after $60 \mathrm{~min}$. But $\mathrm{GO}_{\mathrm{HDA}-0.25 \mathrm{Mg}^{2+}}$ and $\mathrm{GO}_{\mathrm{HDA}}$ still remain stable, even when the water was stirred by glass rod, indicating that $\mathrm{GO}_{\mathrm{HDA}-0.25 \mathrm{Mg}^{2+}}$ membrane can overcome the swelling problem in water like $\mathrm{GO}_{\mathrm{HDA}}$.

\section{Permeance of cross-linking GO}

We performed dyes permeation tests to verify the water flux and the reject rate of $\mathrm{GO}, \mathrm{GO}_{\mathrm{HDA}}$ and $\mathrm{GO}_{\mathrm{HDA}-0.25 \mathrm{Mg}^{2+}}$ membranes. As shown in Fig. 3a-c, HDA resulted in a decrease in water flux for rejecting methylene blue, pararosaniline and rhodamine $\mathrm{B}$ from $12.5 \mathrm{~L} \mathrm{~m}^{-2} \mathrm{~h}^{-1} \mathrm{bar}^{-1}, 30.6 \mathrm{~L} \mathrm{~m}^{-2} \mathrm{~h}^{-1} \mathrm{bar}^{-1}$ and $23.5 \mathrm{~L} \mathrm{~m}^{-2} \mathrm{~h}^{-1}$ bar $^{-1}$ for GO membrane to $11.2 \mathrm{~L} \mathrm{~m}^{-2} \mathrm{~h}^{-1} \mathrm{bar}^{-1}, 10.8 \mathrm{~L} \mathrm{~m}^{-2} \mathrm{~h}^{-1}$ bar $^{-1}$ and $13.4 \mathrm{~L} \mathrm{~m}^{-2} \mathrm{~h}^{-1} \mathrm{bar}^{-1}$ for the $\mathrm{GO}_{\mathrm{HDA}}$ membrane, respectively. But it didn't make much difference to the reject rate. The performance of $\mathrm{GO}_{\mathrm{HDA}}$ is consistent with early reports. ${ }^{9,10}$ In addition, we also observed the performance of the GO membranes controlled only by $\mathrm{Mg}^{2+}\left(\mathrm{GO}_{\mathrm{Mg}^{2+}}\right)$, which prepared with the same experimental process as did the crosslinking experiments, as shown in Fig. S3. $\dagger$ The water flux of $\mathrm{GO}_{\mathrm{Mg}^{2+}}$ for rejecting methylene blue was $39 \mathrm{~L} \mathrm{~m}^{-2} \mathrm{~h}^{-1} \mathrm{bar}^{-1}$, which is only slightly higher than that of GO. In contrast, $\mathrm{GO}_{\mathrm{HDA}-0.25 \mathrm{Mg}^{2+}}$ membranes have ultrahigh water flux, which were $143.2,114.4$ and $144.2 \mathrm{~L} \mathrm{~m}^{-2} \mathrm{~h}^{-1} \mathrm{bar}^{-1}$ for the three dyes, respectively, while still rejected dyes as those of $\mathrm{GO}_{\mathrm{HDA}}$. Interestingly, the water fluxes are nearly 10 times higher than those of $\mathrm{GO}_{\mathrm{HDA}}$ membranes without sacrificing dyes rejection, as shown in Fig. 3d. It further demonstrated that $\mathrm{GO}_{\mathrm{HDA}-0.25 \mathrm{Mg}^{2+}}$ membrane has much better uniformity and lower mass transfer resistance than that of $\mathrm{GO}_{\mathrm{HDA}}$. We also listed the separation performance of GO-based membranes previously reported for organic dyes. As shown in Table $1, \mathrm{GO}_{\mathrm{HDA}-0.25 \mathrm{Mg}^{2+}}$ showed great advantage on the water flux.

The stability of water flux and dyes rejection of $\mathrm{GO}_{\mathrm{HDA}}$ $0.25 \mathrm{Mg}^{2+}$ and $\mathrm{GO}_{\mathrm{HDA}}$ membranes was analyzed. The fluxes were measured for $2 \mathrm{~h}$ and recorded every $10 \mathrm{~min}$ after adding DI water into the feed side. As shown in Fig. $3 \mathrm{~d}-\mathrm{f}$, the fluxes of the $\mathrm{GO}_{\mathrm{HDA}-0.25 \mathrm{Mg}^{2+}}$ and $\mathrm{GO}_{\mathrm{HDA}}$ were about $114.4 \mathrm{~L} \mathrm{~m}^{-2} \mathrm{~h}^{-1} \mathrm{bar}^{-1}$ and $11.2 \mathrm{~L} \mathrm{~m}^{-2} \mathrm{~h}^{-1} \mathrm{bar}^{-1}$, respectively, which were very stable during the whole filtration process compared with the flux varies from $35.7 \mathrm{~L} \mathrm{~m}^{-2} \mathrm{~h}^{-1}$ bar $^{-1}$ to $4.3 \mathrm{~L} \mathrm{~m}^{-2} \mathrm{~h}^{-1}$ bar $^{-1}$ of the $\mathrm{GO}$ membrane. It demonstrated that $\mathrm{GO}_{\mathrm{HDA}-0.25 \mathrm{Mg}^{2+}}$ and $\mathrm{GO}_{\mathrm{HDA}}$ all have the outstanding stability in filtration process, which is attributed to the $\mathrm{C}-\mathrm{N}$ bond formed between GO and HDA.

The performance of the GO membranes, which were synergistically cross-linked by $\mathrm{K}^{+}\left(\mathrm{GO}_{\mathrm{HDA}-\mathrm{K}^{+}}\right)$or $\mathrm{Fe}^{3+}\left(\mathrm{GO}_{\mathrm{HDA}-\mathrm{Fe}^{3+}}\right)$ were also observed, as shown in Fig. S4. $\uparrow$ The membrane cross-linked with $\mathrm{K}^{+}$and $\mathrm{Fe}^{3+}$ ions and $\mathrm{HDA}\left(\mathrm{GO}_{\mathrm{HDA}-\mathrm{K}^{+}}\right.$and $\left.\mathrm{GO}_{\mathrm{HDA}^{-}-\mathrm{Fe}^{3+}}\right)$ exhibited water flux of $40.1 \mathrm{~L} \mathrm{~m}^{-2} \mathrm{~h}^{-1} \mathrm{bar}^{-1}$ and $140.6 \mathrm{~L} \mathrm{~m}^{-2}$ $\mathrm{h}^{-1} \mathrm{bar}^{-1}$, respectively, while keeping $>99 \%$ rejection for methylene blue, indicating high multivalence metal ions are beneficial to permeability. Compared with these tested metal cations, the $\mathrm{Mg}^{2+}$ ions still have the greatest advantage in terms of water flux. 

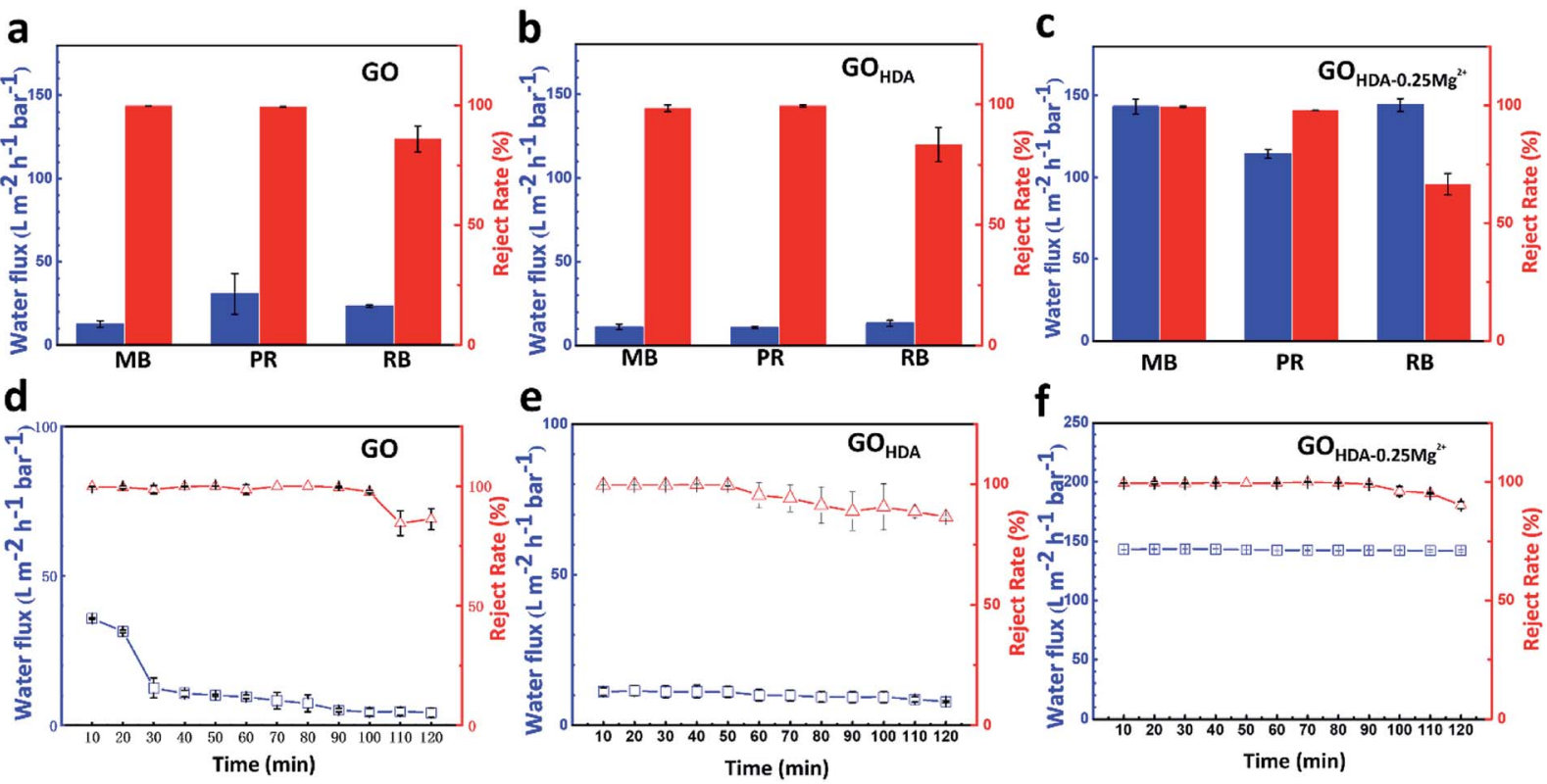

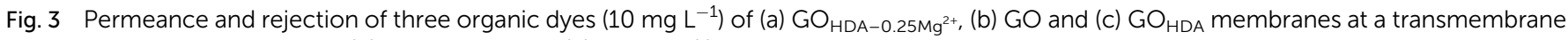

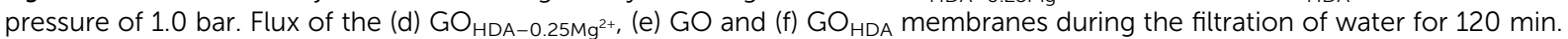

\section{Effect of thickness and concentration of $\mathrm{Mg}^{2+}$ on permeance of cross-linking GO membrane}

It is clear that $\mathrm{Mg}^{2+}$ can greatly improve the permeance of the cross-linking membrane. Considering potential influence of $\mathrm{Mg}^{2+}$ concentration on cross-linking, we prepared GO membranes with a series of concentrations (from $0.25 \mathrm{M}$ to $0.025 \mathrm{M}$ ) of $\mathrm{Mg}^{2+}$, which were named as $\mathrm{GO}_{\mathrm{HDA}-0.25 \mathrm{Mg}^{2+}}, \mathrm{GO}_{\mathrm{HDA}-}$ $0.125 \mathrm{Mg}^{2+}, \mathrm{GO}_{\mathrm{HDA}-0.05 \mathrm{Mg}^{2+}}$, and $\mathrm{GO}_{\mathrm{HDA}-0.025 \mathrm{Mg}^{2+}}$, respectively. As shown in Fig. $4 \mathrm{a}-\mathrm{c}$, we used $\mathrm{GO}_{\mathrm{HDA}-\mathrm{Mg}^{2+}}$ membranes, which have a thickness of about $200 \mathrm{~nm}$, to investigate the permeation with different concentrations of $\mathrm{Mg}^{2+}$. As the concentration of $\mathrm{Mg}^{2+}$ decreased from $0.25 \mathrm{M}$ to $0.025 \mathrm{M}$, the water fluxes gradually reduced from 142.2 to $71.5 \mathrm{~L} \mathrm{~m}^{-2} \mathrm{~h}^{-1} \mathrm{bar}^{-1}$ for methylene blue, from 114.4 to $70.3 \mathrm{~L} \mathrm{~m}^{-2} \mathrm{~h}^{-1} \mathrm{bar}^{-1}$ for pararosaniline, and from 114.2 to $71.6 \mathrm{~L} \mathrm{~m}^{-2} \mathrm{~h}^{-1} \mathrm{bar}^{-1}$ for rhodamine $\mathrm{B}$, respectively, while the rejections remained constant. In the case of the lowest $\mathrm{Mg}^{2+}$ concentration of $0.025 \mathrm{M}$, the water fluxes were still about seven times that without $\mathrm{Mg}^{2+}$. It further indicated that $\mathrm{Mg}^{2+}$ plays a key role in improving the water flux of cross-linking GO membrane.

In addition, the effect of thickness of membrane on water flux and reject rate were also explored, as shown in Fig. 4d. The thickness of membrane can be controlled by the amount of GO suspension loaded on the substrate. $\mathrm{GO}_{\mathrm{HDA}-0.25 \mathrm{Mg}^{2+} \text { membranes }}$ with four thickness of $100 \mathrm{~nm}, 200 \mathrm{~nm}, 300 \mathrm{~nm}$ and $400 \mathrm{~nm}$, were prepared by using $1.5 \mathrm{~mL}, 3 \mathrm{~mL}, 4.5 \mathrm{~mL}$ and $6 \mathrm{~mL}$ of mixture GO solution. With increasing of the thickness of the membrane, the water flux decreases dramatically from 251.5 to $90.2 \mathrm{~L} \mathrm{~m}^{-2} \mathrm{~h}^{-1}$ bar $^{-1}$ while the rejection remained constant, suggesting that the highest water flux could be further improved

Table 1 Permeation of graphene-based membrane for dyes rejection ${ }^{a}$

\begin{tabular}{|c|c|c|c|c|}
\hline CCG & Methylene blue & $>99$ & $3.26-21.81$ & 12 \\
\hline $\mathrm{TMC}+\mathrm{GO}$ & Methylene blue & $46-66$ & $8-27.6$ & 14 \\
\hline rGO/MCNT & Rhodamine B & 100 & 52.7 & 28 \\
\hline NSC-GO & Rhodamine B & $87 \pm 3$ & 279 & 29 \\
\hline \multirow[t]{3}{*}{$\mathrm{GO}_{\mathrm{HDA}-0.25 \mathrm{Mg}^{2+}}$} & Methylene blue & 99.42 & 143.2 & This work \\
\hline & Pararosaniline & 97.90 & 114.4 & \\
\hline & Rhodamine B & 66.54 & 144.2 & \\
\hline
\end{tabular}

${ }^{a}$ CCG: chemically converted graphene; PECs: polyelectrolyte complexes; TMC: 1,3,5-benzenetricarbonyl trichloride; MCNT: multi-walled carbon nanotube; NSC-GO: ultrafiltration nanostrand-channelled GO. 

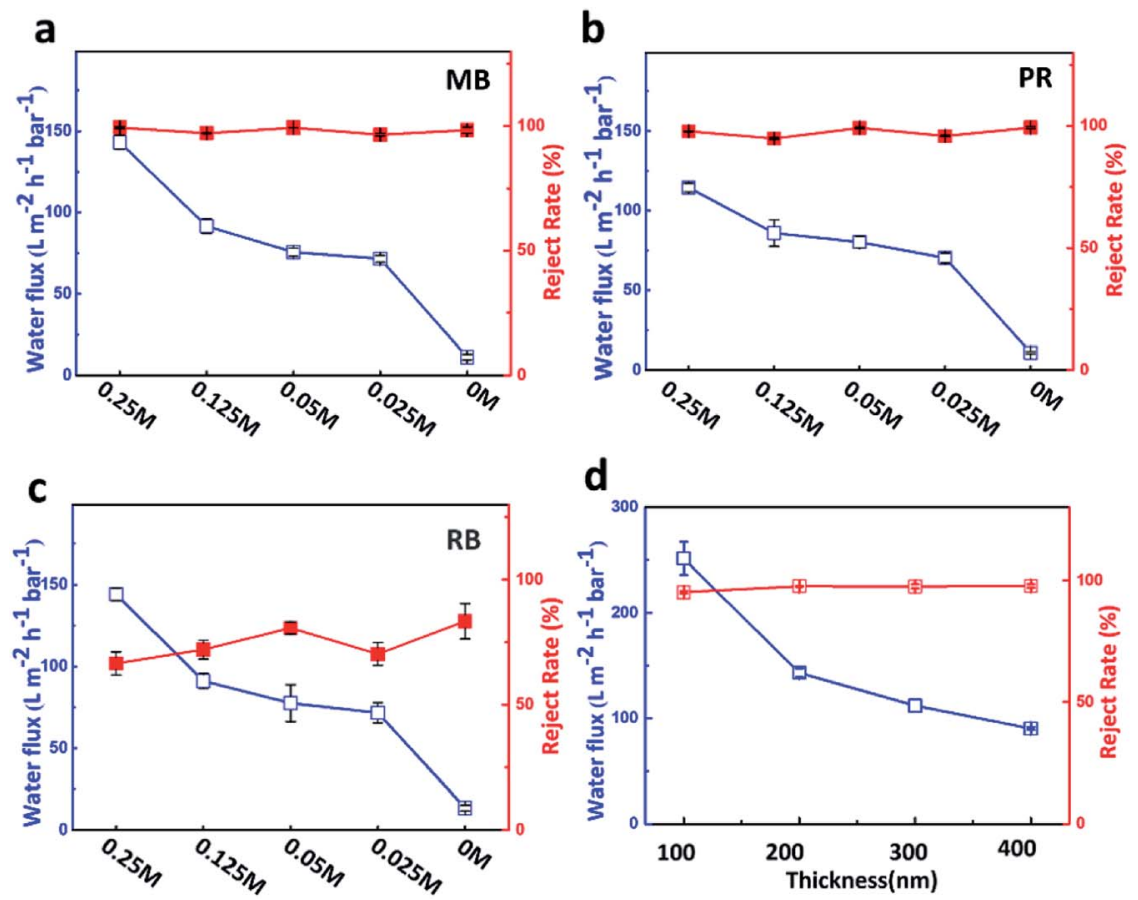

Fig. 4 Permeance and reject rate of (a) methylene blue, (b) pararosaniline and (c) rhodamine $\mathrm{B}\left(10 \mathrm{mg} \mathrm{L}^{-1}\right)$ by GO $\mathrm{HDA}_{-\mathrm{Mg}^{2+}} \mathrm{membrane} \mathrm{formed}$

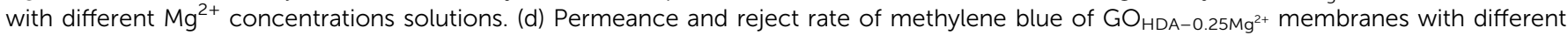
thickness.

without sacrificing dyes rejection by controlling membrane thickness.

\section{The cation- $\pi$ interactions between hydrated $\mathrm{Mg}^{2+}$ and GO} sheets

To illustrate the underlying physical mechanism of $\mathrm{Mg}^{2+}$ taking place in the process, we performed UV absorption spectra of GO solutions mixed with $0.25 \mathrm{M}, 0.125 \mathrm{M}, 0.05 \mathrm{M}$, and $0.025 \mathrm{M}$ $\mathrm{Mg}^{2+}$, respectively. As shown in Fig. 5, the characteristic peak at $\sim 230 \mathrm{~nm}$ was attributed to the $\pi-\pi^{*}$ from the aromatic double

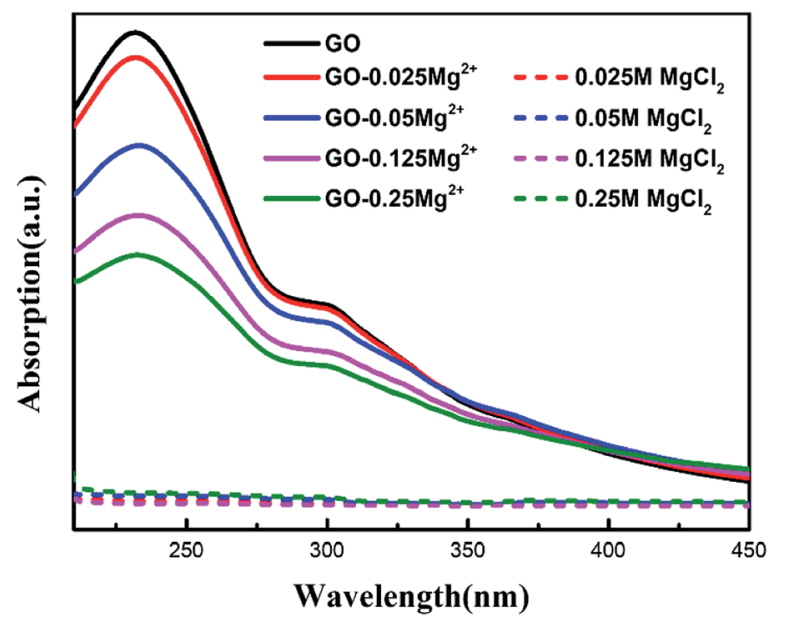

Fig. 5 UV absorption spectra of $\mathrm{GO}$ suspension (100 $\left.\mathrm{mg} \mathrm{L}^{-1}\right) 1: 1$ mixed with $0.025 \mathrm{M}, 0.125 \mathrm{M}, 0.05 \mathrm{M}$ and $0.25 \mathrm{M} \mathrm{Mg}^{2+}$ solutions. bond conjugate. ${ }^{13,16,31}$ Compared with the GO in pure water, the intensity of GO mixed with $\mathrm{Mg}^{2+}$ solution was significantly decreased. It is showed that the trend was positively correlated with the concentration of $\mathrm{Mg}^{2+}$ solution. It indicated that the conjugated double bonds of aromatic groups in GO are greatly influenced by the concentration of salt solution. ${ }^{11}$ Our previous density functional theory computations show that high multivalence metal ions should have a strong cation- $\pi$ interaction with the graphene sheet, resulting in ions enrichment on surface of graphene. ${ }^{16}$ Hence, the enrichment of $\mathrm{Mg}^{2+}$ on GO sheets based on the strong cation $-\pi$ interaction, can promoted reasonable cross-linking and improved the water channels of membrane in terms of flatness and low mass transfer resistance. As a result, the $\mathrm{GO}_{\mathrm{HDA}-\mathrm{Mg}^{2+}}$ membrane has ultrahigh water flux, while keeping high dyes rejection.

\section{Conclusions}

In summary, we successfully enhanced the permeance of the cross-linking GO membrane by using the cation- $\pi$ interaction between $\mathrm{Mg}^{2+}$ and aromatic ring structure. The enhancement is positively correlated with the concentration of $\mathrm{Mg}^{2+}$. It not only overcomes the swelling of GO membrane and enhances the stability of membrane, but also solves limitation of low water flux. This is attributed to the presence of $\mathrm{Mg}^{2+}$, which can prevent excessive chemical cross-linking and improves the water channels of membrane in terms of flatness and low mass transfer resistance surface during the cross-linking reaction. Therefore, the $\mathrm{GO}_{\mathrm{HDA}-0.25 \mathrm{Mg}^{2+}}$ exhibits ultrahigh water flux (143.2 $\mathrm{L} \mathrm{m}^{-2} \mathrm{~h}^{-1} \mathrm{bar}^{-1}$ ) and high reject rate for dyes in the 
filtration experiment. The $\mathrm{GO}_{\mathrm{HDA}-\mathrm{Mg}^{2+}}$ membranes also have an outstanding stability in filtration process, which is attributed to the $\mathrm{C}-\mathrm{N}$ bond formed between GO and HDA. This study suggests that other ions that have strong cation- $\pi$ interaction, could have a similar effect like $\mathrm{Mg}^{2+}$, may opens a new door for the chemical cross-linking mode of GO membrane combined with ions.

\section{Conflicts of interest}

There are no conflicts to declare.

\section{Acknowledgements}

This work was supported by the National Natural Science Foundation of China (No. U1832150, 11875236), the Scientific Research and Developed Fund of Zhejiang A \& F University (No. 2017FR032).

\section{Notes and references}

1 V. V. Neklyudov, N. R. Khafizov, I. A. Sedov and A. M. Dimiev, Phys. Chem. Chem. Phys., 2017, 19, 17000-17008.

2 P. Sun, K. Wang and H. Zhu, Adv. Mater., 2016, 28, 22872310 .

3 N. V. Medhekar, A. Ramasubramaniam, R. S. Ruoff and V. B. Shenoy, ACS Nano, 2010, 4, 2300-2306.

4 Y. Tu, M. Lv, P. Xiu, T. Huynh, M. Zhang, M. Castelli, Z. Liu, Q. Huang, C. Fan, H. Fang and R. Zhou, Nat. Nanotechnol., 2013, 8, 594.

5 B. Mi, Science, 2014, 343, 740.

6 J. Ran, C. Chu, T. Pan, L. Ding, P. Cui, C.-F. Fu, C.-L. Zhang and T. Xu, J. Mater. Chem. A, 2019, 7, 8085-8091.

7 K. H. Thebo, X. Qian, Q. Zhang, L. Chen, H.-M. Cheng and W. Ren, Nat. Commun., 2018, 9, 1486.

8 S. Zheng, Q. Tu, J. J. Urban, S. Li and B. Mi, ACS Nano, 2017, 11, 6440-6450.

9 W.-S. Hung, C.-H. Tsou, M. De Guzman, Q.-F. An, Y.-L. Liu, Y.-M. Zhang, C.-C. Hu, K.-R. Lee and J.-Y. Lai, Chem. Mater., 2014, 26, 2983-2990.

10 S. Xia, M. Ni, T. Zhu, Y. Zhao and N. Li, Desalination, 2015, 371, 78-87.

11 L. Chen, G. Shi, J. Shen, B. Peng, B. Zhang, Y. Wang, F. Bian, J. Wang, D. Li, Z. Qian, G. Xu, G. Liu, J. Zeng, L. Zhang, Y. Yang, G. Zhou, M. Wu, W. Jin, J. Li and H. Fang, Nature, 2017, 550, 380.
12 Y. Han, Z. Xu and C. Gao, Adv. Funct. Mater., 2013, 23, 36933700 .

13 W. Chen, S. Chen, T. Liang, Q. Zhang, Z. Fan, H. Yin, K.-W. Huang, X. Zhang, Z. Lai and P. Sheng, Nat. Nanotechnol., 2018, 13, 345-350.

14 M. Hu and B. Mi, Environ. Sci. Technol., 2013, 47, 3715-3723.

15 J. Shen, G. Liu, K. Huang, W. Jin, K.-R. Lee and N. Xu, Angew. Chem., 2015, 127, 588-592.

16 G. Shi, J. Liu, C. Wang, B. Song, Y. Tu, J. Hu and H. Fang, Sci. Rep., 2013, 3, 3436.

17 W. S. Hummers and R. E. Offeman, J. Am. Chem. Soc., 1958, 80, 1339.

18 C. Zhang, D. M. Dabbs, L.-M. Liu, I. A. Aksay, R. Car and A. Selloni, J. Phys. Chem. C, 2015, 119, 18167-18176.

19 E. Fuente, J. A. Menéndez, M. A. Díez, D. Suárez and M. A. Montes-Morán, J. Phys. Chem. B, 2003, 107, 6350-6359.

20 A. Bagri, C. Mattevi, M. Acik, Y. J. Chabal, M. Chhowalla and V. B. Shenoy, Nat. Chem., 2010, 2, 581.

21 Y. Shen, H.-B. Zhang, H. Zhang, W. Ren, A. Dasari, G.-S. Tang and Z.-Z. Yu, Carbon, 2013, 56, 132-138.

22 J. Cai, J. Chen, P. Zeng, Z. Pang and X. Kong, Chem. Mater., 2019, 31, 3729-3735.

23 Y. Yang, J. Wang, J. Zhang, J. Liu, X. Yang and H. Zhao, Langmuir, 2009, 25, 11808-11814.

24 N. I. Kovtyukhova, P. J. Ollivier, B. R. Martin, T. E. Mallouk, S. A. Chizhik, E. V. Buzaneva and A. D. Gorchinskiy, Chem. Mater., 1999, 11, 771-778.

25 S. H. Shim, K. T. Kim, J. U. Lee and W. H. Jo, ACS Appl. Mater. Interfaces, 2012, 4, 4184-4191.

26 H.-K. Jeong, Y. P. Lee, R. J. W. E. Lahaye, M.-H. Park, K. H. An, I. J. Kim, C.-W. Yang, C. Y. Park, R. S. Ruoff and Y. H. Lee, J. Am. Chem. Soc., 2008, 130, 1362-1366.

27 N. Wang, S. Ji, G. Zhang, J. Li and L. Wang, Chem. Eng. J., 2012, 213, 318-329.

28 K. Goh, W. Jiang, H. E. Karahan, S. Zhai, L. Wei, D. Yu, A. G. Fane, R. Wang and Y. Chen, Adv. Funct. Mater., 2015, 25, 7348-7359.

29 H. Huang, Z. Song, N. Wei, L. Shi, Y. Mao, Y. Ying, L. Sun, Z. Xu and X. Peng, Nat. Commun., 2013, 4, 2979.

30 L. Chen, J.-H. Moon, X. Ma, L. Zhang, Q. Chen, L. Chen, R. Peng, P. Si, J. Feng, Y. Li, J. Lou and L. Ci, Carbon, 2018, 130, 487-494.

31 H. Yorita, K. Otomo, H. Hiramatsu, A. Toyama, T. Miura and H. Takeuchi, J. Am. Chem. Soc., 2008, 130, 15266-15267. 